\title{
Diagnosa Radiografi dan Penanganan Penyakit Periodontal pada Anjing Yorkshire Terrier
}

\author{
Muhammad Faiz Hafizhuddin ${ }^{1}$, Siti Zaenab ${ }^{2}$, Deni Noviana ${ }^{3 *}$ \\ ${ }^{1}$ Program Sarjana Fakultas Kedokteran Hewan, Institut Pertanian Bogor \\ ${ }^{2}$ My Vets Animal Clinic, Kemang, Jakarta Selatan \\ ${ }^{3}$ Departemen Klinik Reproduksi dan Patologi, Fakultas Kedokteran Hewan, Institut Pertanian Bogor
}

ABSTRAK: Tujuan studi kasus ini adalah mengetahui gambaran radiografi serta penanganan kasus penyakit periodontal pada anjing Yorkshire Terrier. Radiografi dilakukan dengan menggunakan teknik paralel pada gigi premolar dan molar mandibula anjing. Studi kasus ini menggunakan anjing jantan jenis Yorkshire Terrier. Hasil pengambilan gambar radiografi menunjukan adanya penurunan densitas pada sekitar gigi molar 308 yang memiliki nilai indeks plak, gingivitis, dan furcation yang tinggi dibandingkan dengan gigi yang memiliki nilai indeks yang kecil yaitu gigi 306. Selain itu, pada gigi 308 didapatkan sulkus gingiva sedalam $0.3 \mathrm{~mm}$. Pencabutan gigi anjing dilakukan pada seluruh gigi incisor mandibula. Berdasarkan studi kasus yang dilakukan, diagnosa untuk melakukan penanganan penyakit periodontal dapat dilakukan dengan radiografi.

Kata kunci:

anjing, densitas, gigi, penyakit periodontal, radiografi

\section{PENDAHULUAN}

Anjing merupakan hewan kesayangan yang banyak digemari oleh banyak orang. Perawatan yang kurang baik dapat menyebabkan penyakit, salah satunya penyakit periodontal. Penyakit periodontal dapat menyebabkan hewan mengalami kesulitan makan, bau mulut, kesulitan membersihkan dirinya (grooming), dan menyebabkan beberapa penyakit sistemik seperti komplikasi kardiovaskular, rheumatoid arthritis, gangguan kehamilan (Oz dan Puleo 2011) dan artherosclerosis (Kortegaard et al. 2014). Penentuan penilaiaan status periodontal dapat ditentukan dengan hasil radiografi (Kortegaard et al. 2014). Tindakan yang dilakukan untuk mengurangi mikroba dalam menangani penyakit periodontal antara lain scaling, root planning (Fernandes et al. 2010), dan mengontrol infeksi yang terjadi di area gingiva (Soares et al. 2010).

\section{- ANAMNESIS DAN SINYALEMEN}

Studi kasus ini menggunakan anjing jantan jenis Yorkshire bernama Twix berumur 10 tahun. Berdasarkan pemeriksaan fisik yang dilakukan anjing memiliki berat badan $2.8 \mathrm{Kg}$, dengan suhu $38.5^{\circ} \mathrm{C}$. Hewan datang dengan keluhan bau mulut. Hewan masih memiliki nafsu makan yang baik. Pakan yang diberikan adalah pakan kering.

\section{- GEJALA KLINIS}

Berdasarkan hasil pemeriksaan keadaan gigi anjing menunjukan bahwa anjing kehilangan gigi Incisivus (101, 102, 103, 201, 202, 203) Caninus (204) Premolar (105, 406, 407) Molar (108). Keadaan gigi yang memiliki nilai indeks plak, furcation, dan gingivitis yang tinggi antara lain Molar (109, 208, 209, 308, 309, 408, dan 409). Selain itu hewan juga mengalami halithosis (bau mulut).

\section{- HASIL DAN PEMBAHASAN}

Berdasarkan hasil gambaran radiografi pada gambar 1 memperlihatkan gigi, gusi, sulkus gingiva, dan tulang mandibula. Berdasarkan densitasnya tulang dan gigi memiliki densitas yang lebih besar dibandingkan dengan gusi. Hal ini dikarenakan enamel yang melapisi gigi mengandung $96 \%$ bahan inorganik berupa hydroxyapatite crystal dan $4 \%$ bahan organic berupa air dan jaringan fibrosa. Bahan inorganik tersebut merupakan terkeras dalam tubuh dan hanya melapisi bagian crown gigi (Unit RVC 2002).

Hasil analisis gambaran radiografi dengan ImageJ®, didapatkan nilai intensitas densitas dari periodontal sekitar gigi premolar 306 memiliki nilai yang lebih besar dibandingkan dengan gigi molar 308. Penurunan densitas menun- 
jukkan hilangnya jaringan yang melekatkan gigi dengan gusi akibat efek peradangan oleh toksin bakteri dan sistem kekebalan tubuh inang (Caiafa 2006). Hasil gambaran radiografi juga menunjukan kedalaman sulkus gingiva pada gigi molar 308 sebesar $4 \mathrm{~mm}$. Menurut Pieri et al. (2012) sulkus gingiva pada anjing normal yang diukur dengan probe adalah 1-3 mm. Sulkus gingiva yang memiliki kedalaman lebih dari $3 \mathrm{~mm}$ akan membentuk periodontal pocket yang dapat menjadi tempat berkembang biaknya mikroorganisme.

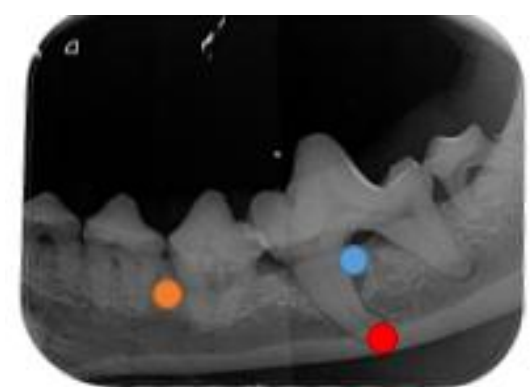

Gambar 1 Hasil radiografi gigi premolar dan molar dengan titiktitik lokasi pengukuran densitas.

Keterangan:

Densitas periodontal gigi molar 306

Densitas periodontal gigi premolar 308 dan kedalaman sulkus gingiva

Jarak antara akar gigi pertama molar 308 dengan tulang mandibula

Hasil gambaran radiografi menunjukan bahwa akar pertama dari gigi molar 308 telah menembus tulang mandibula sedalam $12 \mathrm{~mm}$ sehingga menyisakan tebal tulang mandibular $9 \mathrm{~mm}$. Menurut Niemiec (2010) penyakit periodontal dapat menyebabkan berkurang atau hilangnya tulang mandibula. Hal tersebut dapat meningkatkan risiko fraktur iatrogenic saat ekstraksi gigi.

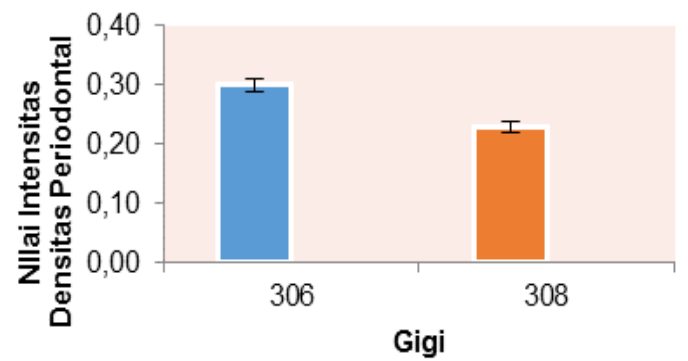

Gambar 2 Grafik nilai intensitas densitas periodontal sekitar gigi 306 dan 308

Berdasarkan hasil pemeriksaan gigi dan radiografi, dilakukan scaling dan ekstraksi pada beberapa gigi. Pembersihan gigi dengan menggunakan alat ultrasonic scaler dilakukan setelah dilakukan pembersihan gigi menggunakan extraction forceps. Pembersihan gigi menggunakan extraction forceps bertujuan untuk menghilangkan plak atau kalkulus yang telah terbentuk pada gigi. Menurut Caiafa (2006) ada beberapa alasan melakukan ekstraksi antara lain fraktur pada gigi, supernumery, dan penyakit periodontal dengan nilai indeks furcation dan mobilitas yang tinggi.

Gigi yang masih ada digosok (polishing) menggunakan alat polisher yang mengandung fluoride. Tujuan polishing adalah menghilangkan sisa plak yang masih tersisa. Terapi penyakit periodontal bertujuan mengontrol mikroorgaanisme, mengembalikan keadaan anatomi dan fisiologi hewan, dan mencegah melekatnya plak yang disebabkan bakteri pada permukaan gigi (Pieri et al. 2012). Setelah penanganan penyakit periodontal, perlu dilakukan pemeriksaan gigi rutin selama 5-7 hari, perlu diberikan antibiotik selama 2 minggu dan pemberian pakan lunak untuk membantu proses persembuhan.

\section{- SIMPULAN}

Diagnosa penyakit periodontal dapat dilakukan dengan radiografi. Penanganan penyakit periodontal pada anjing ditentukan dengan melihat hasil pemeriksaan klinis gigi yang dicatat pada diagram gigi serta hasil gambaran radiografi.

\section{- INFORMASI PENULIS}

Penulis untuk Korespondensi

deni@ipb.ac.id

\section{- PUSTAKA ACUAN}

Caiafa T. 2006. The Complete Dental Prophylaxis: Protocols including Oral Examination, Oral Radiography, Canine and Feline Extraction Techniques. Di dalam: Proceedings of annual seminars of the companion animal society of the NZ Veterinary Nurses Association [Internet]. [2006 Januari dan tempat pertemuan tidak diketahui]; NZ: New Zealand Veterinary Association. Hlm 35-35, 46-47.

Fernandes LA, Martins TM, Almeida JMD, Nagata MJH, Theodoro LH, Garcia VG, Bosco AF. 2010. Experimental periodontal disease treatment by subgingival irrigation with tetracycline hydrochloride in rats. J Appl Oral Science. 18(6):635-40.

Kortegaard HE, Eriksen T, Baelum V. 2014. Screening for Periodontal disease in research dogs - a methodology study. Acta Vet Scand. 56(1):77.

Niemiec BA. 2010. The Importance of Dental Radiology. EJCAP 20(3): 219-229.

Oz HS, Puleo DA. 2011. Animal Models for Periodontal Disease. $J$ Biomed Biotechnol. 2011(2011): 754857.

Pieri FA, Daibert APF, Bourguignon E, Moreira MAS. 2012. Periodontal Disease in Dogs, A Bird's-Eye View of Veterinary Medicine [internet]. [diunduh 2015 Juni 29]; 119-140. Tersedia pada: http://www.intechopen.com/books/a-bird-s-eyeview-of-veterinary-medicine/periodontal-disease-in-dogs.

Soares PBF, Magalhaes D, Neto AJF, Castro CG, Filho PCFS, Soares CJ. 2010. Effect of Periodontal Therapies on Indirect Restoration: A Scanning Electron Microscopic Analysis. Braz Dent J. 21(2): 130-136.

Unit RVC. 2002. Veterinary Dentistry Basics. [Internet]. [diunduh 7 Juli 2015]. Tersedia pada: http://www.rvc.ac.uk/review/Dentistry/.html 